\title{
Maternal and fetal outcome in pregnancy with heart disease in tertiary care hospital in India
}

\author{
Saima Salam, Saba Mushtaq, Khalid Mohi-ud-Din, Irfan Gul*, Asifa Ali
}

Department of Obstetrics and Gynecology, Government Medical College, Srinagar, Jammu and Kashmir, India

Received: 26 June 2017

Accepted: 25 July 2017

\section{*Correspondence:}

Dr. Irfan Gul,

E-mail: irfanbeigh33@gmail.com

Copyright: (C) the author(s), publisher and licensee Medip Academy. This is an open-access article distributed under the terms of the Creative Commons Attribution Non-Commercial License, which permits unrestricted non-commercial use, distribution, and reproduction in any medium, provided the original work is properly cited.

\begin{abstract}
Background: Cardiac disease is an important cause of maternal mortality and morbidity both in antepartum and postpartum period. The overall incidence of heart disease in pregnancy is $<1 \%$. Objective of present study was to determine maternal outcome in pregnant women with heart diseases in terms of fetal complication, maternal complication and Mode of delivery.

Methods: This study was conducted in the Department of Obstetrics and Gynaecology at Government Lalla Ded Hospital, an associated of Government Medical College, Srinagar which is the sole tertiary care referral centre in the valley. 90 women with heart disease which were previously established or diagnosed during pregnancy were enrolled in the study.

Results: In 90 women pregnancies was complicated by heart disease in the study. The prevalence of heart disease amongst all pregnancies found in hospital was $4.3 \%$. The principal cause of cardiac lesion was Rheumatic heart disease (RHD) (56.6\%) while congenital heart disease was seen in 13.3\%. Among the women who had RHD, mitral stenosis seen in $21(23.3 \%)$ was most common lesion and Multiple cardiac lesions 21 (24.4\%) women. Among the women with congenital cardiac disease, mitral valve prolapse was most common constituting 5 (5\%) cases. Cardiomyopathy was the most common constituting 7 (7.3\%). Heart failure developed in $10(11.1 \%)$ whose NYHA class changed from class I/II to class III/IV. Majority of the women delivered by caesarean section 33 (36.7\%) while $(35.6 \%)$ had a normal vaginal delivery with spontaneous onset of labour. $7 \%$ had assisted instrumental vaginal delivered. $9 \%$ women had first trimester abortion. There were 4 maternal deaths. $85.6 \%$ live births were observed in these women. No baby had congenital heart disease. $72.8 \%$ babies born weighed more than $2 \mathrm{~kg}$.

Conclusions: This study concluded that pre- pregnancy diagnosis, counselling, appropriate referral, antenatal supervision and delivery at equipped centre improve the pregnancy with heart disease outcome for both mother and baby.
\end{abstract}

Keywords: Cardiomyopathy, Mitral valve stenosis, Pregnancy, Rheumatic heart disease

\section{INTRODUCTION}

Cardiac disease is one of the important cause of maternal mortality and morbidity both in antepartum and postpartum period. Cardiac disease in pregnancy is broadly divided into congenital and acquired. The acquired group includes RHD, cardiomyopathies and ischemic heart disease. Of these, in developing countries rheumatic heart disease is the commonest type, whereas cardiomyopathies and congenital heart disease one more common in developed countries. Among all presentations of Rheumatic heart disease, mitral stenosis is the predominant lesion and accounts for nearly three quarters of all cases. 
Cardiomyopathies are being increasingly recognized with three main types - the dilated (including peripartum cardiomyopathy), restrictive and hypertrophic variety. The overall incidence of heart disease in pregnancy is $<1 \%$. $^{1}$ The presence of maternal heart disease effects on the fetus in a number of ways. The risk of spontaneous miscarriage and therapeutic abortion increases in women with heart disease. ${ }^{2}$ The children borne from the mother with congenital heart disease are at increased risk of congenital heart disease. The overall risk of inheriting polygenic cardiac disease is $3-5 \%$, as compared to $1 \%$ risk in the general population. ${ }^{3}$ This risk is dependent on the condition of affected parent and there is an increased risk if a previous siblings are affected. ${ }^{4}$ Some cardiac medications can have adverse effects on the fetus such as ACE inhibitors, warfarin and statins. ACE inhibitors well known for the teratogenic effects especially during first trimester and should therefore be avoided during this period. ${ }^{5}$ Exposure during second and third trimester can lead to marked fetal hypotension and decreased renal blood flow. If the use of ACE inhibitors is necessary, the lowest possible dose should be used and amniotic fluid levels and fetal growth should be monitored carefully. The use of Statins during pregnancy is controversial However, epidemiological data suggests that statins are not major teratogens. So, it is still advisable to avoid statins during the first trimester. ${ }^{6}$ The relative immunocompromised state of pregnancy increases the risk of infection (e.g. urinary tract infection). This can increase the heart rate, potentially worsening cardiac function. Approximately, $1 \%$ of all pregnancies are complicated by cardiovascular diseases.

Cardiovascular abnormalities are considered most important non-obstetric cause of morbidity and mortality during pregnancy. In women of childbearing age, Rheumatic and Congenital heart diseases are currently the most frequently found cardiovascular diseases. In developed countries, the prevalence of pregnancy complicated by rheumatic heart disease (RHD) has decreased. Previous ratio of 3:1 for RHD to congenital heart disease complicating pregnancy is now essentially reversed but in developing countries rheumatic heart diseases are still predominant and continues to be a major cause of maternal morbidity and mortality. In western countries, maternal heart diseases are the third most common cause of maternal death and complicates 1-3\% of pregnancies. ${ }^{7,8}$ Cardiac diseases can complicate $1-4 \%$ of pregnancies in women without pre-existing cardiac abnormalities. Cardiac disease is one of the three major indirect causes of maternal mortality in India. Pregnancy can cause certain therapeutic problems, which may threaten maternal and fetal well-being and survival. ${ }^{9}$

The circulatory changes of pregnancy in the presence of maternal heart disease may result in adverse consequences even death of the mother or fetus. ${ }^{10}$ Pregnancy is a challenge to women with heart disease because of the $50 \%$ increase in plasma volume and sixfold increase in the risk of thrombosis. ${ }^{11}$ In developing countries, a large number of women become pregnant prior of seeking therapeutic intervention for cardiac lesions and many of them are only diagnosed with heart disease during pregnancy. ${ }^{12}$ Detailed assessment of patient throughout pregnancy may lead to initial discovery of heart disease. If diagnosed early, and managed properly with multidisciplinary approach, collaboration of a team of trained obstetricians, cardiologist, anaesthetist, pediatrician and nurse, it results in successful outcome for mother and child in majority of cases. $^{13}$

In women with normal reserve, Hemodynamic changes of normal pregnancy are well tolerated. However, decompensation occurs in diseased heart, with resultant increase in maternal morbidity and mortality. It is natural to expect that fetus will also be compromised in these mothers as fetal health depends upon adequate and continuous supply of well oxygenated maternal. ${ }^{7}$ In western countries, maternal cardiac disease complicates $1-3 \%$ of pregnancies and is the third common cause of maternal death during pregnancy. ${ }^{7,8}$ Cardiac diseases complicate $1-4 \%$ of pregnancies in women without preexisting cardiac abnormalities. Heart disease is one of the 3 major indirect causes of maternal mortality in India. Most data concerning pregnancy course in heart disease patients are anecdotal reports or are in small series; only a few comprehensive studies are available. ${ }^{14-19}$ The primary objective of the present study is to assess the effect of heart disease in pregnancy and its outcome.

\section{METHODS}

This study was conducted in the Department of Obstetrics and Gynecology at Government Lalla Ded Hospital, an associated of Government Medical College, Srinagar which is the sole tertiary care referral centre in the valley. 90 women with heart disease which were previously established or diagnosed during pregnancy were enrolled in the study. Included in our study were all pregnant women with congenital or acquired cardiac lesions or delivered patients with heart disease who were referred to our hospital but those with associated medical disorders like Diabetes mellitus, pulmonary disease, renal disease or any other endocrinological disease were excluded from this study. A structured detailed proforma was used to gather the essential information regarding heart disease in pregnancy. Baseline data recorded included were age, parity, gestational age, cardiac lesions, use of cardiac medications, thorough clinical examination including chest and cardiovascular auscultation, ECG and echocardiographic assessment of left and right ventricular systolic function. The mode of delivery whether vaginal, use of instruments and the need for LSCS was duly recorded.

\section{RESULTS}

A total of 90 women where pregnancy was complicated by heart disease were included in the study. The 
prevalence of heart disease amongst all pregnancies found in the hospital was $4.3 \%$, The age of patients ranged from 20-35 years with maximum number of patients in 20-30 years age group (74.5\%). In this study, most of the patients were primigravida (60\%). The Rheumatic Heart disease was the principal cause of heart disease amongst all pregnancies. Congenital heart disease was present in $13.3 \%$ patients.

Table 1: Age distribution of patients.

\begin{tabular}{|c|c|c|}
\hline Age (years) & No. & $\%$ \\
\hline$<20$ & 3 & 3.3 \\
\hline $20-25$ & 34 & 37.8 \\
\hline $26-30$ & 33 & 36.7 \\
\hline $31-35$ & 12 & 13.3 \\
\hline$>35$ & 8 & 8.9 \\
\hline Total & 90 & 100 \\
\hline
\end{tabular}

Among the women who had Rheumatic heart disease, Mitral Valve stenosis being the most common lesion and was seen in $21(23.3 \%)$. Multiple cardiac lesions were present in $22(24.4 \%)$ women. Among the women with congenital cardiac disease, mitral valve prolapse was most common lesion constituting $5(5 \%)$ cases.

Table 2: Distribution of cardiac lesion.

\begin{tabular}{|llll|}
\hline Cardiac lesions & & No. & $\%$ \\
\hline Rheumatic & Single valve lesion & 29 & 32.2 \\
\cline { 2 - 4 } heart disease & Multiple valve lesions & 22 & 24.4 \\
\hline Congenital & 12 & 13.3 \\
\hline Prior cardiac surgery & 7 & 7.8 \\
\hline Miscellaneous & 20 & 22.2 \\
\hline Total & 90 & 100 \\
\hline
\end{tabular}

Cardiomyopathy was the most common cardiac disease in the miscellaneous group, constituting 7 (7.8\%). Among the studied pregnant women with heart disease, heart failure developed in $10(11.1 \%)$ cases whose NYHA class changed from class $1 / 11$ to class $111 / 1 \mathrm{~V}$. Majority of women delivered by cesarean section 33 (36.7\%). Thirty-two (35.6\%) subjects had a normal vaginal delivery with spontaneous onset of labour. Seven (7\%) had assisted instrumental vaginal delivery.

Table 3: Maternal outcome of pregnancy in term of mode of delivery.

\begin{tabular}{|llll|}
\hline Pregnancy & & No. & $\%$ \\
\hline LSCS & & 33 & 36.7 \\
\hline Vaginal & Spontaneous labour & 32 & 35.6 \\
\cline { 2 - 4 } delivery & Induced labour & 5 & 5.6 \\
\hline $\begin{array}{l}\text { Instrumental } \\
\text { delivery }\end{array}$ & Ventouse & 6 & 6.7 \\
\hline Oermination & Onevitable abortion & 7 & 7.8 \\
\cline { 2 - 4 } $\begin{array}{l}\text { Termegnancy } \\
\text { of pregnancy }\end{array}$ & $\begin{array}{l}\text { Medical termination } \\
\text { of pregnancy }\end{array}$ & 2 & 2.2 \\
\hline Maternal death & & 4 & 4.4 \\
\hline
\end{tabular}

Out of 90 patients, there were four $(4.4 \%)$ maternal deaths. Nine $(9 \%)$ women had first trimester abortions. Among all the babies born alive none had congenital heart disease. There were about $77(85.6 \%)$ live births observed in these women. Among all babies born 56 (72.8\%) weighted more than 2 Kgs.

Table 4: Perinatal outcome in maternal heart disease pregnancy.

\begin{tabular}{|llll|}
\hline \multirow{2}{*}{ Perinatal outcome } & & No. & $\%$ \\
\hline \multirow{2}{*}{ Apgar score } & Still & 13 & 14.4 \\
\cline { 2 - 4 } & Live & 77 & 85.6 \\
\hline \multirow{2}{*}{ NICU admission } & $<9 / 10$ & 19 & 24.7 \\
\hline \multirow{2}{*}{ Neonatal death } & $\geq 9 / 10$ & 58 & 75.3 \\
\hline & Yes & 22 & 28.6 \\
\cline { 2 - 4 } & No & 55 & 71.4 \\
\hline & Yes & 2 & 2.6 \\
\hline
\end{tabular}

\section{DISCUSSION}

This study was conducted in the postgraduate Department of Obstetrics and Gynaecology, Lalla Ded hospital affiliated with GMC, Srinagar in total of 90 women This study aimed at assessment of maternal and neonatal complications associated with cardiac disease in pregnancy. Various studies estimated that $0.3 \%$ to $3.5 \%$ of all pregnancies are complicated by heart disease. In the present study, the prevalence of $4.3 \%$ was found which was same as that of the study conducted by Puri S et al. ${ }^{20}$ In the current study, majority of the patients were in the age group of 20-30 years $(74.5 \%)$ and most of them were either primigravidae or primipara $(60 \%)$. This was comparable to Vidyadharet al were $70 \%$ were either primigravida or primipara. ${ }^{21}$

In the current study RHD (56.6\%) was the principal cardiac lesion and mitral stenosis was the most common cardiac lesion $(23.3 \%)$. These results were in consensus with Vidyadharet al, Mazhar SB et al, Devabhaktula et al, and $\mathrm{N}$ Bhatla et al. ${ }^{1,21-23}$ However incidence of RHD has been greatly reduced in developed countries by widespread use of antibiotics effective against the streptococcal infections. Thus, current study indirectly indicates inadequate treatment of streptococcal infections in childhood and adolescence. Echocardiography was done routinely in our patients. Twenty-two (24.4\%) patients had multiple cardiac lesions. Echocardiography was helpful for early and accurate evaluation of cardiac lesions.

In this study, $35.6 \%$ women had spontaneous vaginal delivery as compared to $41 \%$ (Nilajkumar et al); $24 \%$ (Alireza et al); 76.2\% (Mazhar et al); 73.5\% (Hameed et al); $62.8 \%$ (Vidyadhar et al) in other studies. ${ }^{21,22,24-26}$ Cesarean Section (36.7\%) was done only for obstetrical indications. Nilajkumar et al reported caesarean in $20.6 \%$; $9.5 \%$ by Mazhar et al; Alireza et al $(76 \%) .{ }^{22,24,25}$ In the present study,55 of women underwent labour 
induction as compared to $15 \%$ in study conducted by Hameed et al and Pratibha D et al. ${ }^{23,26}$ In the evaluation of pregnancy with cardiac disease $7.8 \%$ of patients had inevitable abortions and $2.2 \%$ had to undergone MTP which was comparable to Suman et al and Mazhar et al studies. $^{20,22}$ Mortality in pregnant females with cardiac disease is mainly due to cardiac failure and pulmonary oedema. Four females in our study died mainly due to cardiac failure, sepsis and shock which was comparable to Hameed et al, Mazhar et al, Alireza et al, Verena et al, Akhtar et al and Sheetal CN et $\mathrm{al}^{29} .^{22,25-28}$

In the present study, $21(27.8 \%)$ babies were born who weighed less than $2 \mathrm{~kg} 56$ babies. Seventy-seven live births were observed in these women and 13 still births which was comparable to Mazharet al. ${ }^{22}$

\section{CONCLUSION}

Present data supports the fact that the prognosis of pregnant women with heart disease has improved, leading frequently to successful outcome. Proper evaluation of maternal prognosis prior to conception and adequate clinical follow up during pregnancy are both fundamental measures for obtaining a satisfactory outcome in these patients.This study concluded that pre- pregnancy diagnosis, counseling, appropriate referral, routine antenatal supervision and delivery at an equipped centre improve the pregnancy with heart disease outcome for both mother and baby. Cardiac failure is a serious complication and often leads to maternal death. We therefore stress the need to monitor cardiac patient for early detection and management of heart failure throughout the course of pregnancy, labor and puerperium.

\section{Funding: No funding sources}

Conflict of interest: None declared

Ethical approval: The study was approved by the Institutional Ethics Committee

\section{REFERENCES}

1. Bhatla N, Lal S, Behera G, Kriplani A, Mittal S, Agarwal $\mathrm{N}$ et al. Cardiac disease in pregnancy. Int $\mathrm{J}$ Gynecol Obstet. 2003;82(2):153-9.

2. Siu SC, Colman JM, Sorensen S, Smallhorn JF, Farine D, Amankwah KS et al. Adverse neonatal and cardiac outcomes are more common in pregnant women with cardiac disease. Circulation. 2002;105:2179-84.

3. Romano Zelekha O, Hirsh R, Blieden L, Green M, Shohat $\mathrm{T}$. The risk for congenital heart defects in offspring of individuals with congenital heart defects. Clin Genet. 2001;59:325-9.

4. Burn J, Brennan P, Little J, Holloway S, Coffey R, Somerville $\mathrm{J}$ et al. Recurrence risks in offspring of adults with major heart defects: results from first cohort of British collaborative study. Lancet. 1998;351:311-6.
5. Cooper WO, Hernandez Diaz S, Arbogast PG, Dudley JA, Dyer S, Gideon PS et al. Major congenital malformations after first trimester exposure to ACE inhibitors. $\mathrm{N}$ Engl J Med. 2006;354(23):2443-51.

6. Kazmin A, Garcia Bournissen F, Koren G. Risks of statin use during pregnancy: a systematic review. J Obstet Gynaecol Can. 2007;29(11):906-8.

7. Arafeh JM, Baird SM. Cardiac disease in pregnancy. Crit Care Nurs Q. 2006;29:35-52.

8. Dobbenga-Rhodes YA, Prive AM. Assessment and evaluation of the woman with cardiac disease during pregnancy. J Perinat Neonatal Nurs. 2006;20:295302.

9. Scirica BM, O'Gara PT. Valvular heart disease in pregnancy. Curr Cardiol Rep. 2006;8:83-9.

10. Siu SC, Colman JM, Sorensen S, Smallhorn JF, Farine D, Amankwah KS et al. Adverse neonatal and cardiac outcomes are more common in pregnant women with cardiac disease. Circulation. 2002;105:2179.

11. Steer P. Heart disease in pregnancy. women's health medicine. Med Prob Pregnancy. 2005;2(2):18-21.

12. Sawhney H, Aggarwal N, Suri V, Vasishta K, Sharma Y, Grover A. Maternal and perinatal outcome in rheumatic heart disease. Int J Gynecol Obstet. 2003;80:9-14.

13. Trinidad D, Cox RA. Heart diseases during pregnancy. P R Health Sci J. 2006;25:259-65.

14. Avila WS, Rossi EG, Ramires JA, Grinberg M, Bortolotto MR, Zugaib $M$ et al. Pregnancy in patients with heart disease: experience with 1000 cases. Clin Cardiol. 2003;26:135-142.

15. Siu SC, Sermer M, Harrison DA, Grigoriadis E, Liu $\mathrm{G}$, Sorensen $\mathrm{S}$ et al. Risk and predictors for pregnancy-related complications in women with heart disease. Circulation. 1997;96:2789-94.

16. Siu SC, Sermer M, Colman JM, Alvarez AN, Mercier LA, Morton BC et al. Prospective multicenter study of pregnancy outcomes in women with heart disease. Circulation. 2001;104:515-21.

17. Siu SC, Sermer M, Colman JM, Alvarez AN, Mercier LA, Morton BC et al. Adverse neonatal and cardiac outcomes are more common in pregnant women with cardiac disease. Circulation. 2002;105:2179-84.

18. Abdel-Hady ES, El-Shamy M, El-Rifai AA, Goda H, Abdel- Samad A, Moussa S. Maternal and perinatal outcome of pregnancies complicated by cardiac disease. Int J Gynaecol Obstet. 2005;90:21-5.

19. Khairy P, Ouyang DW, Fernandes SM, Lee-Parritz A, Economy KE, Landzberg MJ. Pregnancy outcomes in women with congenital heart disease. Circulation. 2006;113:517-524.

20. Puri S, Bharti A, Puri S, Mohan B, Bindal V, Verma $\mathrm{S}$. Maternal heart disease and pregnancy outcomes. JK Sci. 2013;15(1):7-10.

21. Bangal VB, Singh RK, Shinde KK. Clinical study of heart disease complicating pregnancy. IOSR. 2012;2(4):25-8. 
22. Mazhar SB. Fetomaternal outcome in pregnancy with cardiac disease. JCPSP. 2005;15(8):476-80.

23. Pratibha D, Kiranmai D, Rani VU, Vani NG. Pregnancy outcome in chronic rheumatic heart disease. J Obstet Gynecol India. 2009;59(1):41-6.

24. Bagde ND, Bagde MN, Shivkumar PV, Tayade S. Clinical profile and obstetric outcome in pregnancies complicated by heart disease: a five year Indian rural experience. Int J Reprod Contracept Obstet Gynecol. 2013;2(1):52-7.

25. Yaghoubi A, Mirinazhad M. Maternal and neonatal outcomes in pregnant patients with cardiac diseases referred for labour in northwest Iran. JPMA. 2013;63:1496.

26. Hameed A, Karaalp IS, Tummala PP, Wani OR, Canetti M, Akhter MW et al. The effect of valvular heart disease on maternal and fetal outcome of pregnancy. J Am Coll Cardiol. 2001;37(3):893-9.
27. Stangl V, Schad J, Gossing G, Borges A, Baumann G, Stangl K. Maternal heart disease and pregnancy outcome: A single-centre experience. Eur J Heart Failure. 2008;10(9):855-60.

28. Akhter N, Rahman F, Salman M, Anam K, Begum $\mathrm{N}$, Naher $\mathrm{S}$ et al. Valvular heart disease in pregnancy: maternal and fetal outcome. MMJ. 2011;20(3):436-40.

29. Sheela CN, Karanth S, Patil CB. Maternal cardiac complications in women with cardiac disease in pregnancy. Int J Pharm Biomed Res. 2011;2(4):2615 .

Cite this article as: Salam S, Mushtaq S, Mohi-udDin, Gul I, Ali A. Maternal and fetal outcome in pregnancy with heart disease in tertiary care hospital in India. Int J Reprod Contracept Obstet Gynecol 2017;6:3947-51. 